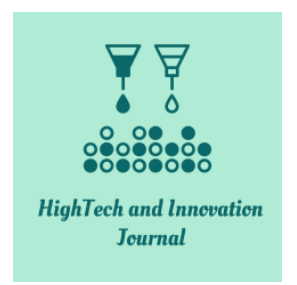

\title{
Implementation of Boost PFC in the Induction Heating System for EMI-RFI Suppression
}

\author{
Rahul Raman ${ }^{\mathrm{a}, \mathrm{b}} \odot$, Debanga Jyoti Baruah ${ }^{\mathrm{a}}$, Saurav Dey ${ }^{\mathrm{a}}$, Padmini Neog ${ }^{\text {a }}$, \\ Kritika Taniya Saharia ${ }^{\text {a }}$ \\ ${ }^{a}$ Department of Electrical Engineering, Jorhat Engineering College, Jorhat, 785007, India. \\ ${ }^{b}$ Department of Electrical Engineering, Indian Institute of Technology (ISM), Dhanbad, 826004, India.
}

Received 29 December 2020; Revised 24 April 2021; Accepted 11 May 2021; Published 01 June 2021

\begin{abstract}
The present work deals with the design and performance analysis of a high frequency resonant inverter based Induction Heating (IH) system employing Boost Power Factor Correction (PFC) technique to overcome the problems due to EMI and RFI. Most of the existing techniques use passive filters for harmonics attenuation that fail to meet the present day requirements because of drawbacks like considerably high THD, poor dynamic performance, etc. This paper presents a new control approach for boost PFC based on inner and outer loops to eliminate the problems due to harmonics in the IH system. The equivalent circuit parameter model of the IH system has been used to analyze the presence of harmonics, and the incorporation of boost PFC at the input of the system shows its elimination as per the stringent EMI-RFI regulations. Moreover, attention has been paid to the design algorithm of the boost PFC, and a detailed mathematical analysis has been done to outline an approach for its parameter selection. A comparative analysis of the IH system with and without the incorporation of the boost PFC has been done in terms of the THD in the input current waveform. The findings of the present work show that the incorporation of Boost PFC eliminates the harmonics in the IH system in a better manner than the existing techniques.
\end{abstract}

Keywords: Induction Heating; PSIM; Harmonics; Resonant Inverter; Boost PFC; EMI; RFI.

\section{Introduction}

Induction Heating (IH) is an efficient and precise method of material heating available in the industry today. Induction heating equipment is extensively used in many industrial and domestic fields [1-3]. The IH principles are useful for domestic cooking purposes as they have more advantages over conventional methods [4-5]. Induction heating equipment also attenuates the injection of current harmonics with the help of interface filters [6-8]. Thus, there are great prospects for the growing use of IHE, which will be of high frequency in the upcoming days. But, this high frequency generates an ample amount of harmonics which flow back to the input and lead to a deterioration of the power standard. Therefore, some new regulations should be introduced in order to triumph over the high frequency of the IHE. New solutions are needed so that the power supply of IHE becomes workable [7-9]. Thus, the use of an inverter comes into the picture, as it has great importance in the operation at high frequency. However, the high frequency of the inverter induces switching operation, which causes voltage distortion and devolves the power standard $[9,10]$. Therefore, by using a modified boost PFC circuit, the difficulties caused by the harmonics can be reduced. They have a great effect in attenuating the inverter harmonics that are probable if the load is nonlinear [10, $11]$.

*Corresponding author: djbaruah1998@gmail.com

doi) http://dx.doi.org/10.28991/HIJ-2021-02-02-05

> This is an open access article under the CC-BY license (https://creativecommons.org/licenses/by/4.0/).

(C) Authors retain all copyrights. 
Namadmalan et al. (2011) proposed both active and passive filters to get rid of the difficulty due to harmonics [12]. There are also some other techniques for controlling the harmonic current, like harmonic current injection, magnetic flux compensation, and series and parallel active filter systems [13-15]. For the inverter of high frequency, there are two kinds of harmonic current, i.e., harmonics at high frequency and harmonics at switching frequency. Many researchers have proposed different methods to get rid of the difficulties due to harmonics [16-19]. Pal et al. (2015) [16] proposed a modified half-bridge inverter fitted to IH equipment to reduce the effect of high frequency harmonics in input current. Figueres et al. [21] proposed a Control Circuit with Load-Current Injection for Single-Phase PowerFactor-Correction Rectifiers. These harmonics are a matter of concern because they flow back to the input side, thus deteriorating the power quality as well as the standardization of current. So, harmonic standards must be followed to attenuate both of them by an appreciable amount. Traditionally, available passive filters had poor dynamic performance. They have poor response under changing load conditions. Moreover, the THD in the input current waveform remains quite high. Also, the active filters have complex circuitry, are bulky and are not cost-effective in IH applications.

Wernekinck et al. (1987) [20] proposed a high frequency AC/DC converter with unity power factor and minimum harmonic distortion. The square root of frequency is inversely proportional to depth of flowing current and the operation of high frequency reduces the skin depth. Therefore, the boost PFC is of outmost importance in this field. This circuit has guaranteed stability and has little to no power consumption. Induction heating equipment operates by the principle of electromagnetic induction. It comprises of work coil and work piece and source of high frequency also. The work coil generates an alternating magnetic field of high frequency [21-24]. Because of this field, there is some physical phenomena like eddy current, hysteresis losses and skin effect. Thus, a high frequency alternating current is flowing because the IH has an electromagnet and electronic oscillator. As a result, it generates an alternating magnetic field. Thus an electric current is generated inside the conductor due to this magnetic field. Due to the continuous magnetization and demagnetization hysteresis loss occurs and it is directly proportional to the frequency [25-27]. On the other hand, an electric current is generated inside the conductor due to this magnetic field and this current is called eddy current which is directly proportional to the square of frequency. Again, as a result of skin effect, at high frequency current is confined in the outer part of the work piece. This effect results in the flow of alternating current in a fine layer in the direction of work piece. Thus heating effect is highly enhanced due to the current induced in the work piece [28-31]. In Section 1.1 proposed IH model has been analyzed with the incorporation of Boost PFC. An approach has been outlined for its parameter selection in continuous conduction mode (CCM) in section 1.2. In section 2, simulation has been done using the equivalent circuit parameter model and the FFT analysis of the input current waveform to compare the results. Finally, in section 3, comparison has been done in terms of THD in the input current waveform.

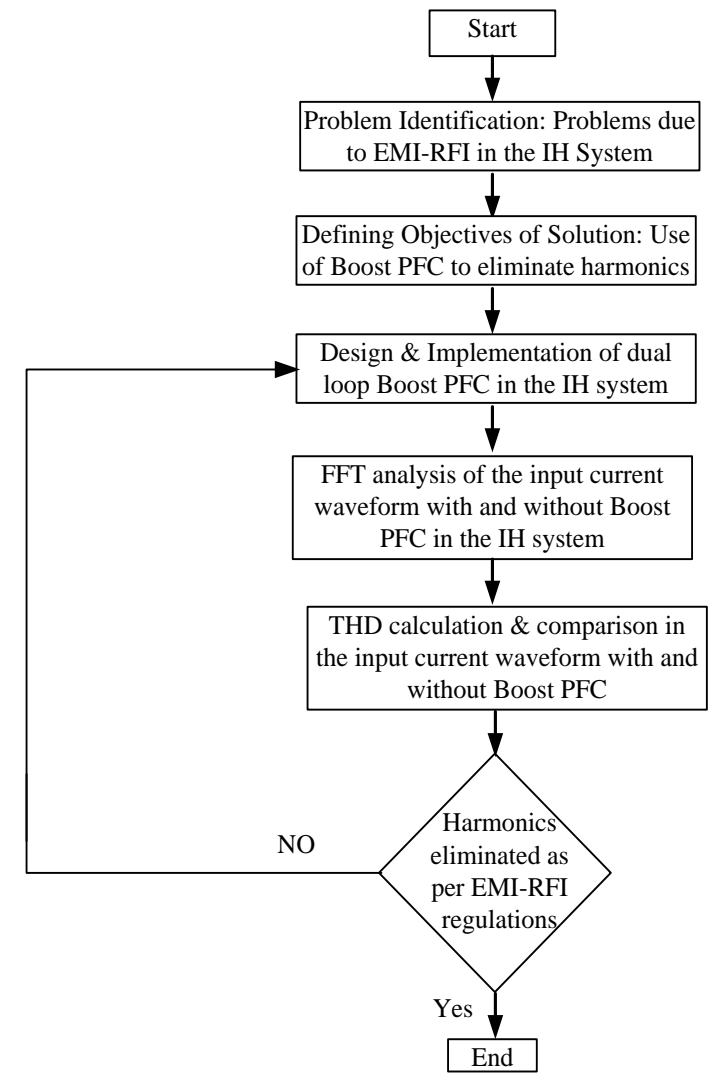

Figure 1. Flow chart showing the research methodology of IH system with Boost PFC 


\subsection{Proposed IH System with Boost PFC}

The Passive filters are essential device for reduction of harmonics. Before the electric current reaches equipment the filters eliminate the harmonics present in the system. However, they have poor dynamic quality and THD is also considerably high. Here, boost PFC is used for harmonic reduction. It reduces the harmonics to some definite extent which is beneficial for industrial as well as domestic purpose. This circuit eliminates the unwanted harmonic components like noise, interference and distortion from the input side for better performance and gives better efficiency. Also, boost PFC offers a good quality power factor with a high output voltage. Boost PFC has efficient energy of storage capacitors and easy switch current sense and gate drive, because of low size boost switch. Here, the boost PFC is connected to the system in parallel which is used to reduce the harmonics to tolerable levels. In this boost PFC, a boost comparator is introduced to control the feedback in such a way that the average current through the inductor is half sinusoidal. Also voltage sensors are used in this filter to sense the input and output AC voltages. A voltage multiplier is used to combine both the input and output voltages. When the voltage goes up the reference will be lower, whether the reference voltage is constant in the circuit. Therefore, the boost PFC suppresses the harmonic current and decrease the voltage distortion which appears in some sensitive part. The power factor is also efficient in this method because harmonic currents divert to the ground and simultaneously provide reactive power to the system. Using this circuit an efficient amount of power will be delivered to the work piece or in the output side. And this is why it is useful to connect the boost PFC in the circuit. By using this circuit, the total harmonic distortion (THD) will be nearly equal to zero.

The basic structure of an IH system with boost PFC is as shown in Figure 2. The presented topology is found, based on the calculation for the values of duty cycle essential for power factor converter, for some definite set-up of Input voltage as well as the Output power within a boost converter. Generally, there are two elements present in the duty cycle (D). D comprises of two elements i.e. $\mathrm{D}_{\mathrm{ON}}$ and $\mathrm{D}_{\mathrm{OFF}}$. The $\mathrm{D}_{\mathrm{ON}}$ states the correlation between the input and output voltage. This is because the changing or shifting frequency is way significant than the line frequency. In the course of changing or shifting period the $\mathrm{V}_{\mathrm{IN}}$ of the PFC is assumed to be continuous. Now the charging voltage and the discharging voltage of inductor in a boost PFC are given below:

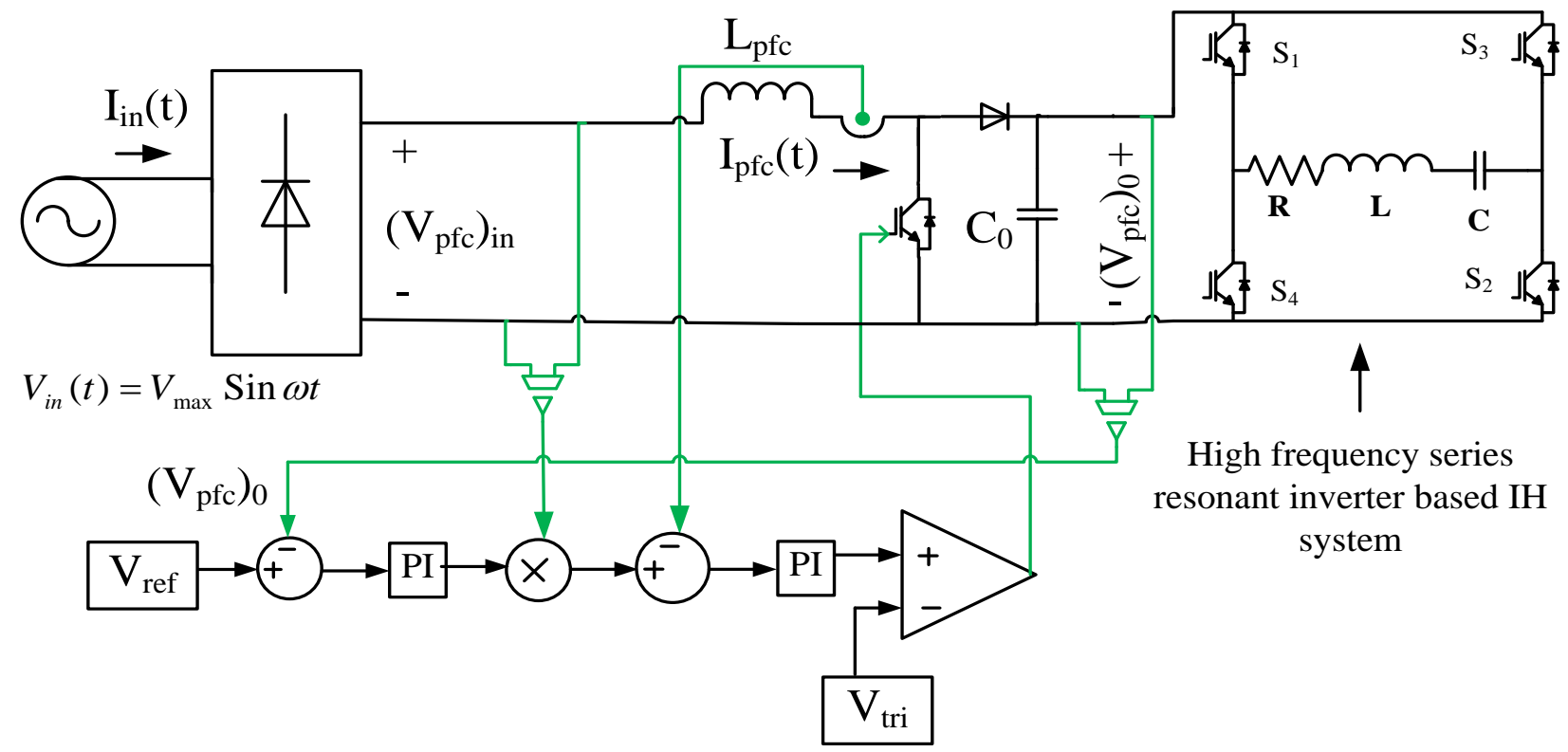

Figure 2. Proposed structure of High frequency series resonant inverter based IH system with PFC comprising of inner and outer loops

$$
\begin{aligned}
& \mathrm{V}_{\mathrm{L}(\text { charge })}=\left(V_{p f c}\right)_{I N} \\
& \mathrm{~V}_{\mathrm{L}(\text { discharge })}=\left(V_{p f c}\right)_{I N}-\left(V_{p f c}\right)_{O}
\end{aligned}
$$

Where, $\mathrm{V}_{\mathrm{IN}}$ is the input and $\mathrm{V}_{\mathrm{o}}$ is the output voltages of the PFC. Also $\mathrm{V}_{\mathrm{L} \text { (charge) }}$ and $\mathrm{V}_{\mathrm{L} \text { (discharge) }}$ are the voltages of the inductor when the transistor is changing from ON state to OFF state or vice-versa. It is significant that the charging current flowing through the inductor is identical to the discharging current. In this analysis the stable current flowing through the inductor is found and followed by some rules and conditions. The given equation must fulfil the continuous conduction mode (CCM). 
$\frac{\mathrm{V}_{\mathrm{L}(\text { charge) }} \times D_{O N} \times\left(T_{p f c}\right)_{O N}}{L_{p f c}}+\frac{V_{L(\text { discharge })} \times\left(1-D_{O N}\right) \times\left(T_{p f c}\right)_{O N}}{L_{p f c}}=0$

Where, $\mathrm{L}_{\mathrm{pfc}}$ indicates the inductance of the inductor of PFC also $T_{O N}$ indicates shifting period. The $\mathrm{D}_{\mathrm{ON}}$ is found by substituting Equation 1 in 2 as follows:

$D_{O N}=\frac{\left(V_{p f c}\right)_{O}-\left(V_{p f c}\right)_{I N}}{\left(V_{p f c}\right)_{O}}$

The values of duty cycle are sufficient in dc-dc converter case, however in ac-dc convertor case it should be mandatory to look into the ripple of $\mathrm{V}_{\mathrm{o}}$ of the PFC.

$V_{\text {ripple }}=\frac{\left(P_{p f c}\right)_{O}}{C_{O} \times \omega \times\left(V_{p f c}\right)_{O}} \times \sin (\omega t)$

Here, $\mathrm{C}_{\mathrm{o}}$ indicates the output capacitance, $\omega$ indicates the pulsating ripple voltage. Here, $\omega$ is equal to twice of line frequency. $\left(\mathrm{P}_{\mathrm{pfc}}\right)_{0}$ indicates output power. The value of $\mathrm{D}_{\mathrm{ON}}$ element is shown below:

$D_{O N}=\frac{\left[\left(V_{p f c}\right)_{O}-V_{\text {ripple }}(m)\right]-\left(V_{p f c}\right)_{I N}(m)}{\left(V_{p f c}\right)_{O}-V_{\text {ripple }}(m)}$

It is mandatory to observe or scrutinize the Doff element because this is the way to gain excellent feasible power factor. This is relevant with inductor energy which is being deposited or disclosed. At the starting the sinusoidal current is growing up but it will diminish just before ending. The inductor voltage $\left(\mathrm{V}_{\mathrm{L}}\right)$ with shifting or switching period $(\mathrm{m})$ is:

$V_{L}(t)=L_{p f c}\left(\frac{d I_{p f c}}{d t}\right) \approx \frac{L_{p f c}}{\left(T_{p f c}\right)_{O N}}\left[I_{p f c}(m+1)-I_{p f c}(m)\right]$

Therefore, The $\mathrm{D}_{\mathrm{OFF}}$ element is given by:

$\mathrm{D}_{\mathrm{OFF}}=\frac{\frac{L_{p f c}}{\left(T_{p f c}\right)_{O N}} \times\left[I_{p f c}(m+1)-I_{p f c}(m)\right]}{\left(V_{p f c}\right)_{O}-V_{\text {ripple }}(m)}$

Where, D is the total duty cycle of PFC, which is the summation of two elements ( $\mathrm{D}_{\mathrm{ON}}$ and $\mathrm{D}_{\mathrm{OFF}}$ ). The final duty cycle is a bit off-balance. These equations for D are logical or reasonable when the converter operates in CCM. For the suggested method, the D values are computed for some particular or distinct performing spot. The values of D are kept in a memory bank for generating the PWM signals, which is directly connected towards transformer of the converter.

\subsection{Design of CCM Mode Boost PFC}

\subsubsection{Inductor Parameters}

In PFC technique employing continuous conduction mode, the current in the inductor does not reach zero during most of the switching cycles. Applying volt-second balance in the inductor $\left(\mathrm{L}_{\mathrm{pfc}}\right)$ for any switching cycle $\mathrm{T}_{\mathrm{pfc}}$.

$\left(\mathrm{V}_{\mathrm{pfc}}\right)_{\mathrm{IN}} \times\left(\mathrm{T}_{\mathrm{pfc}}\right)=\left[\left(\mathrm{V}_{\mathrm{pfc}}\right)_{\mathrm{O}}-\left(\mathrm{V}_{\mathrm{pfc}}\right)_{\mathrm{IN}}\right] \times\left(\mathrm{T}_{\mathrm{pfc}}\right)$

Where, $\quad\left(\mathrm{T}_{\mathrm{pfc}}\right)_{\mathrm{ON}}=\mathrm{D}_{\mathrm{ON}} \times \mathrm{T}_{\mathrm{pfc}},\left(\mathrm{T}_{\mathrm{pfc}}\right)_{\mathrm{OFF}}=\left(1-\mathrm{D}_{\mathrm{ON}}\right) \times \mathrm{T}_{\mathrm{pfc}}$

$D_{O N}=1-\frac{\left(V_{p f c}\right)_{I N}}{\left(V_{p f c}\right)_{O}}$

The Current ripple $\Delta\left(\mathrm{i}_{\mathrm{pfc}}\right)_{\mathrm{L}}$ can be expressed as follows:

$\Delta\left(\mathrm{i}_{\mathrm{pfc}}\right)_{\mathrm{L}}=\frac{\left(\mathrm{V}_{\mathrm{pfc}}\right)_{\mathrm{IN}} \times\left(T_{\mathrm{pfc}}\right)_{O N}}{\mathrm{~L}_{\mathrm{pfc}}}$ 
$\Delta\left(\mathrm{i}_{\mathrm{pfc}}\right)_{\mathrm{L}}=\left(\mathrm{V}_{\mathrm{pfc}}\right) \times\left[\frac{\left.\left(\mathrm{V}_{\mathrm{pfc}}\right)_{\mathrm{O}}-\left(\mathrm{V}_{\mathrm{pfc}}\right)_{\mathbb{N}}\right)}{\mathrm{L}_{\mathrm{pfc}}}\right] \times \mathrm{f}_{\mathrm{pfc}} \times\left(\mathrm{V}_{\mathrm{pfc}}\right)_{\mathrm{O}}$

Where $f_{p f c}=1 / T_{\mathrm{pfc}}=$ Switching Frequency in Boost Converter. In the aforementioned equations, $\mathrm{V}_{\mathrm{pfc}}$ in refers to the instantaneous value of the input voltage to the Boost Converter and it varies with the phase angle.

$\left(\mathrm{V}_{\mathrm{pfc}}\right)_{\mathrm{IN}}(\phi)=\sqrt{2} \times\left(\mathrm{V}_{\mathrm{pfc}}\right)_{\mathrm{rms}} \times \sin \phi$

Where, $\phi(\mathrm{t})=2 \pi \mathrm{ffc}_{\mathrm{pc}} \mathrm{t}$

From Equation 10; it can be found out that $\Delta\left(\mathrm{i}_{\mathrm{pfc}}\right)_{\mathrm{L}}$ attains the maximum value when the input voltage is equal to $\left(\mathrm{V}_{\mathrm{pfc}}\right)_{0} / 2$.

For CCM;

$\left(\mathrm{I}_{\text {pfc }}\right)_{\mathrm{L}-\text { peak }}>\frac{\left(\mathrm{i}_{\mathrm{pfc}}\right)_{\mathrm{L}}}{2}$

Where $\left(\mathrm{I}_{\mathrm{pfc}}\right)_{\mathrm{L}-\mathrm{peak}}$ gives the Peak value of filtered line frequency current; assuming ideal PFC to get a unity Power Factor.

$\left(\mathrm{I}_{\mathrm{pfc}}\right)_{\mathrm{L}-\text { peak }}=\sqrt{2}\left(\mathrm{I}_{\mathrm{pfc}}\right)_{\mathrm{L}, \mathrm{ms}}=\sqrt{2} \frac{\left(\mathrm{P}_{\mathrm{pfc}}\right)_{\mathrm{O}}}{\left(\mathrm{V}_{\mathrm{pfc}}\right)_{\mathrm{ms}} \times \eta_{\mathrm{pfc}}}$

Where $\left(P_{p f c}\right)_{O}=$ Output power of Boost PFC; $\eta_{p f c}=$ Efficiency of Boost PFC.

For CCM, the choice of inductance is quite important and it is done as per the equation given below;

$\mathrm{L}_{\mathrm{pfc}}>\frac{\left(\mathrm{V}_{\mathrm{pfc}}\right)_{\mathrm{rms}}^{2} \times \eta_{\mathrm{pfc}} \times\left[\left(\mathrm{V}_{\mathrm{pfc}}\right)_{\mathrm{O}}-\sqrt{2} \times\left(\mathrm{V}_{\mathrm{pfc}}\right)_{\mathrm{rms}}\right]}{2 \times \mathrm{f}_{\mathrm{pfc}} \times\left(\mathrm{P}_{\mathrm{pfc}}\right)_{\mathrm{O}} \times\left(\mathrm{V}_{\mathrm{pfc}}\right)_{\mathrm{O}}}$

For the purpose of simplicity, the value of inductance ( $\left.\mathrm{L}_{\mathrm{pfc}}\right)$ selected is quite high to that the current ripple can be ignored. The switch $\mathrm{S}_{\mathrm{pfc}}$ conducts only during the ( $\mathrm{D}_{\mathrm{ON}} \mathrm{T}_{\mathrm{pfc}}$ ) of the period $\mathrm{T}_{\mathrm{pfc}}$. Thus the RMS current through the switch in any given switching period can be expressed as follows:

$\left(\mathrm{I}_{\mathrm{s}}\right)_{\mathrm{ms}}(\phi)=\left(\mathrm{I}_{\mathrm{rms}}\right)_{\mathrm{L}}(\phi) \times \sqrt{\left(\mathrm{D}_{\mathrm{ON}}\right)(\phi)}$

Using Equations 9 and 13:

$I_{S, r m s}=\left[\frac{\sqrt{2} \times\left(P_{p f c}\right)_{O} \times|\sin \phi|}{\left(V_{p f c} c_{r m s} \times \eta_{p f c}\right.}\right] \times\left[\sqrt{1-\frac{\sqrt{2} \times\left(V_{p f c}\right)_{r m s} \times|\sin \phi|}{\left(V_{p f c}\right)_{p f c}}}\right]$

Considering the entire time period of the input AC supply;

$\mathrm{I}_{\mathrm{S}, \mathrm{rms}}=\sqrt{\frac{2}{\pi} \int_{0}^{\frac{\pi}{2}}\left[I_{S, \mathrm{rms}}(\varphi)\right]^{2} d \varphi}$

Putting the value of Equation 16 in 17;

$$
\mathrm{I}_{\mathrm{S}, \mathrm{rms}}=\frac{\left(\mathrm{P}_{\mathrm{pfc}}\right)_{\mathrm{O}, \mathrm{rms}}}{\left(\mathrm{V}_{\mathrm{pfc}}\right)_{\mathrm{rms}}} \times \sqrt{1-\frac{8 \times \sqrt{3} \times\left(\mathrm{V}_{\mathrm{pfc}}\right)_{r m s}}{3 \times \pi \times\left(\mathrm{V}_{\mathrm{pfc}}\right)_{\mathrm{O}}}}
$$

The diode in the Boost PFC converter conducts during $\left.\left(1-D_{o f f}\right) T_{p f c}\right)$. The current through the diode in any given switching period is given by:

$$
\left(\mathrm{I}_{\mathrm{pfc}}\right)_{\mathrm{D}, \mathrm{rms}}=\left(\mathrm{I}_{\mathrm{pfc}}\right)_{\mathrm{L}}(\phi) \times \sqrt{1-\mathrm{D}_{\mathrm{ON}}(\phi)}
$$

Thus, 


$$
\left(\mathrm{I}_{\mathrm{pfc}}\right)_{\mathrm{D}, \mathrm{rms}}=\frac{\left(P_{p f c}\right)_{O}}{\left(V_{p f c}\right)_{r m s} \times \eta_{p f c}} \times \sqrt{\frac{8 \times \sqrt{2} \times\left(V_{p f c}\right)_{r m s}}{3 \times \pi \times\left(V_{p f c}\right)_{O}}}
$$

\subsubsection{Capacitor Parameters}

The capacitor present in the output will be charged whenever Boost PFC diode conducts and discharges whenever the switch conducts. The current in the output capacitor of the Boost PFC is given by:

$$
\left(\mathrm{I}_{\mathrm{pfc}}\right)_{\mathrm{C}, \text { rms }}=\frac{\left(\mathrm{P}_{\mathrm{pfc}}\right)_{\mathrm{O}}}{\left(\mathrm{V}_{\mathrm{pfc}}\right)_{\mathrm{O}}} \times \sqrt{\frac{8 \times 1.414 \times\left(\mathrm{V}_{\mathrm{pfc}}\right)_{\mathrm{O}}}{3 \times 3.14 \times\left(\mathrm{V}_{\mathrm{pfc}}\right)_{\mathrm{rms}}}-1}
$$

The current through the output capacitor of the Boost PFC converter comprises of two components that are twice the line frequency as well as the switching frequency.

$$
\begin{aligned}
& \left(\mathrm{I}_{\mathrm{pfc}}\right)_{2 \mathrm{f}, \mathrm{ms}}=\frac{\left(\mathrm{P}_{\mathrm{pfc}}\right)_{\mathrm{O}}}{1.414 \times\left(\mathrm{V}_{\mathrm{pfc}}\right)_{\mathrm{O}}} \\
& \left(\mathrm{I}_{\mathrm{pfc}}\right)_{\mathrm{Cs}, \mathrm{ms}}=\frac{\left(\mathrm{P}_{\mathrm{pfc}}\right)_{\mathrm{O}, \mathrm{rms}}}{\left(\mathrm{V}_{\mathrm{pfc}}\right)_{\mathrm{O}}} \times \sqrt{\frac{8 \times 1.414 \times\left(\mathrm{V}_{\mathrm{pfc}}\right)_{\mathrm{O}}}{3 \times 3.14 \times\left(\mathrm{V}_{\mathrm{pfc}}\right)_{\mathrm{rms}}}-1.5}
\end{aligned}
$$

\section{Simulation Diagram and Results}

In this analysis, a simulation of an IHE is done using various circuit parameters. The PISM software is highly useful for this simulation. At first, a circuit is designed without using any filters. Because of that, high frequency harmonics are generated. Therefore, the circuit is simulated by applying a boost PFC between the rectifier and IHE. The design of the high frequency IHE without and with the use of boost PFC is analyzed in Figures 3 and 6 respectively. The waveforms are also shown corresponding to this circuit design. The PISM platform works efficiently in the simulation of these designs. The simulation design in Figure 3 is the basic diagram of an IHE with no filters. An AC source of $240 \mathrm{~V}, 50 \mathrm{~Hz}$ and transformer (single phase) are connected together. Output of this single phase transformer is connected to a rectifier and output of this rectifier is used as input for the full bridge high frequency inverter with load and is operating under resonating condition. The resistor, inductor and capacitor are connected in series to form the load or in other words the induction heating coil. The simulation circuit design consists of several devices useful in measuring currents and voltages. The current accomplished by the IHE is measured by an ammeter; it is placed at the secondary winding of single phase transformer. The harmonics generated due to the high frequency switching are studied using this current. The switching produces spikes resulting in RFI and EMI i.e. they produce harmonics that deteriorate the power standards because they flow back to the input. This results in huge amount of damage and malfunctioning of the circuit. So these high frequency harmonic currents are attenuated by using boost PFC circuit. In a circuit without a boost PFC, the harmonic components are higher as compared to a circuit with a boost PFC.

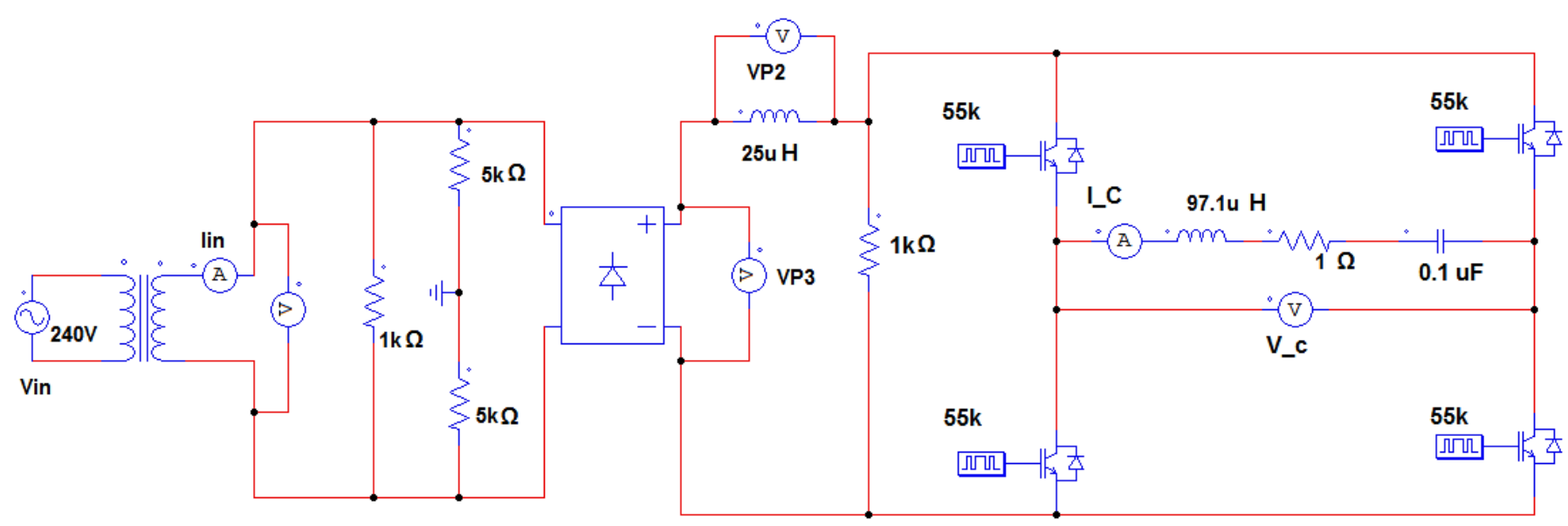

Figure 3. Simulation diagram of IH system without application of Boost PFC 


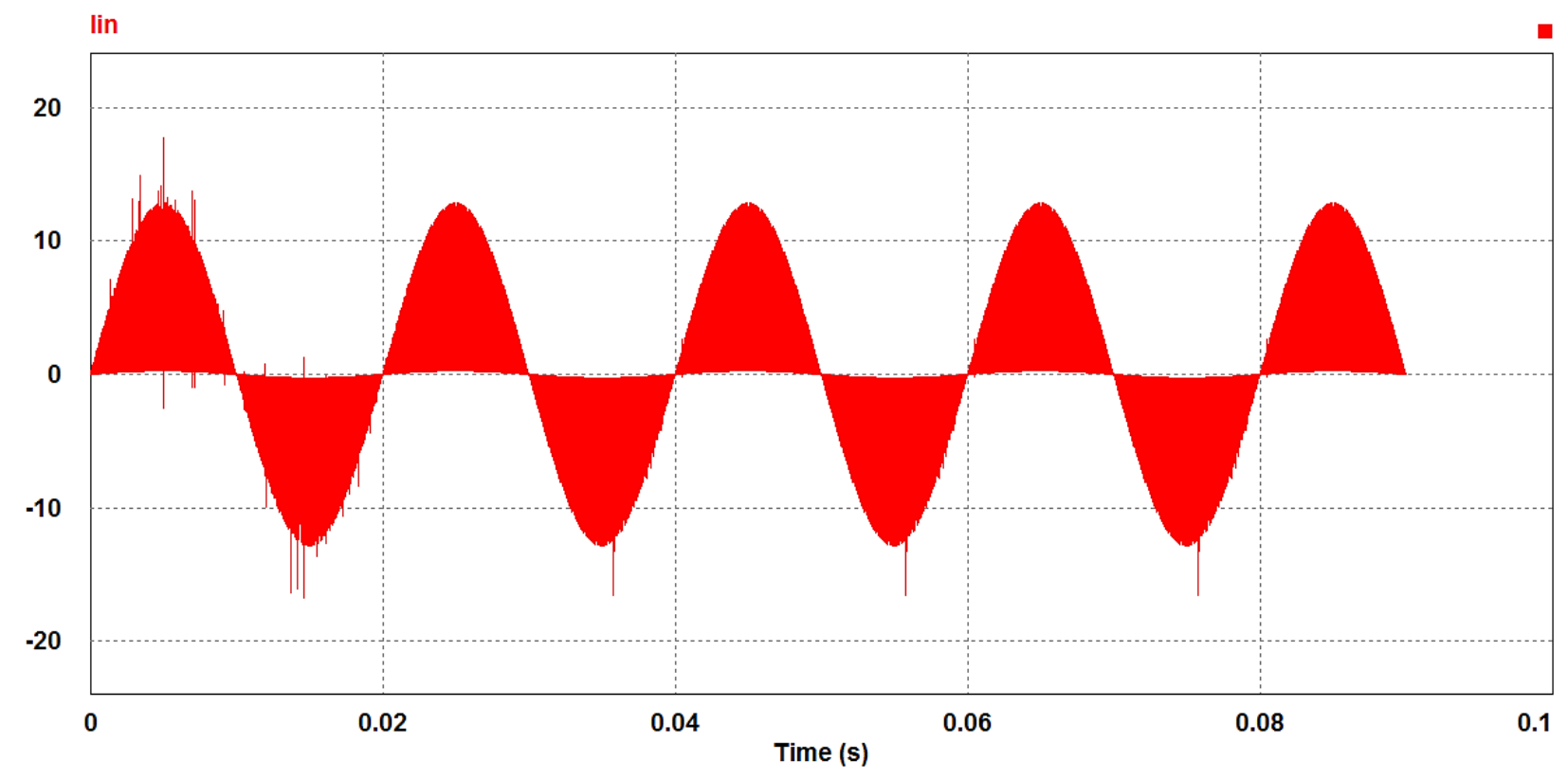

Figure 4. The input current waveform of IH system without Boost PFC

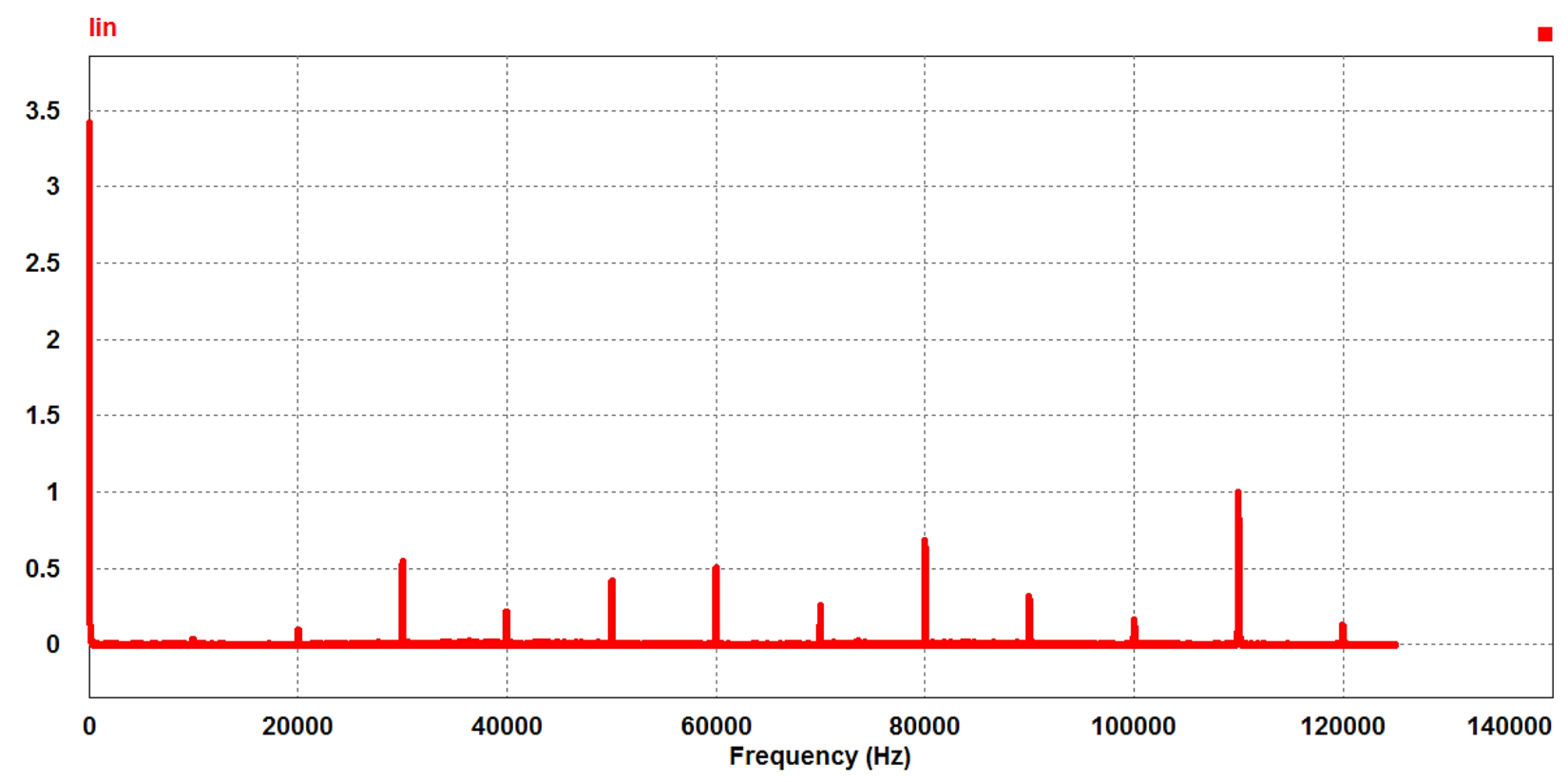

Figure 5. FFT analysis of input current of IH system without Boost PFC

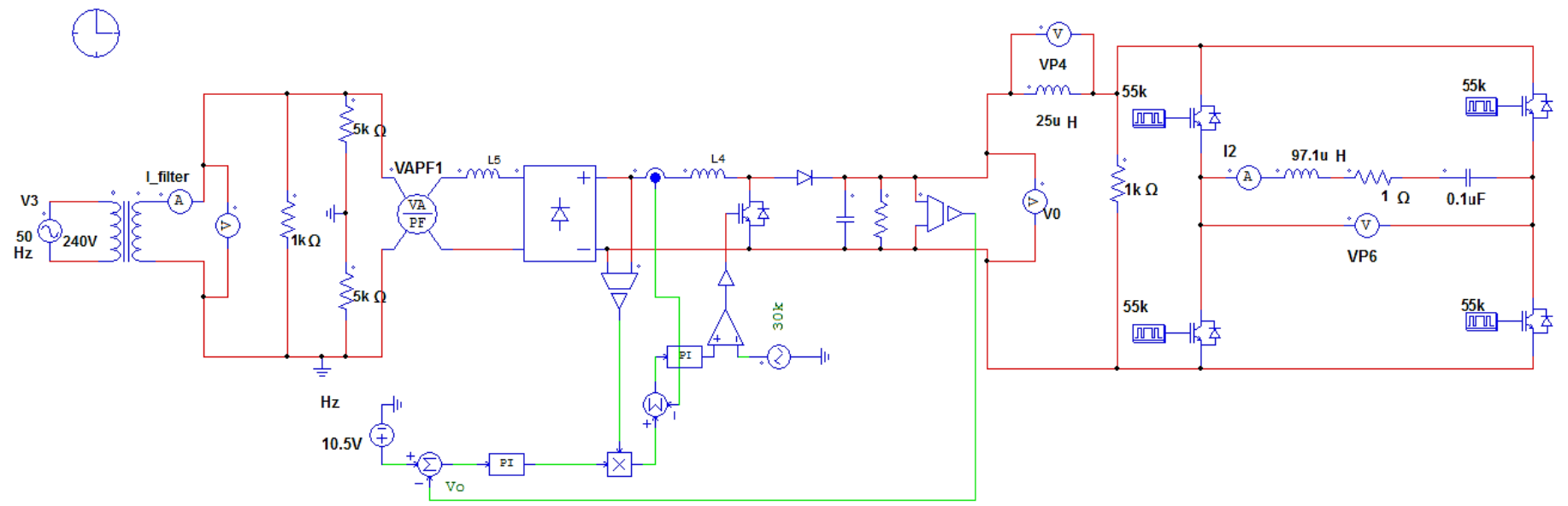

Figure 6. Simulation diagram of IH system with Boost PFC 


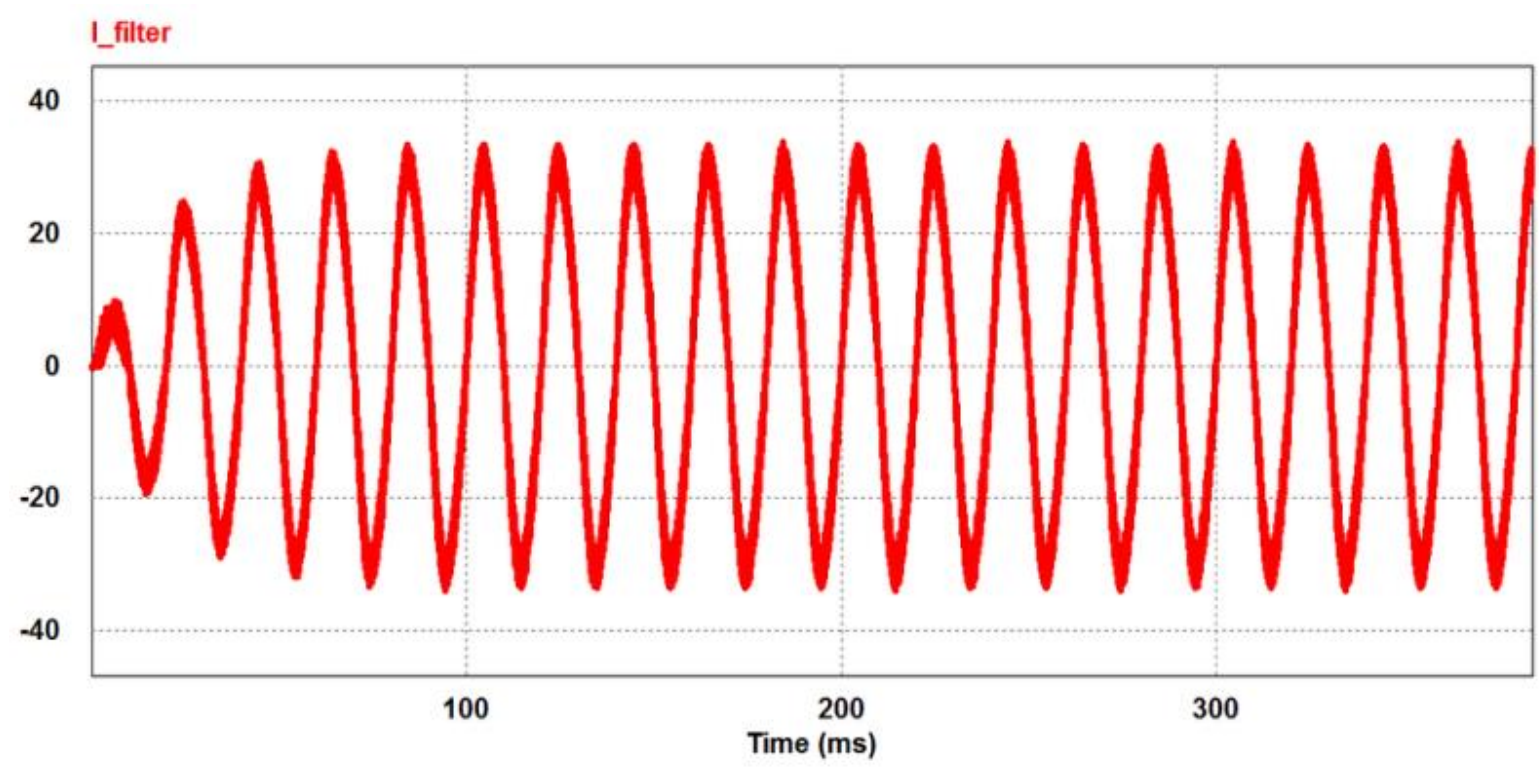

Figure 7. The input current waveform of IH system with Boost PFC

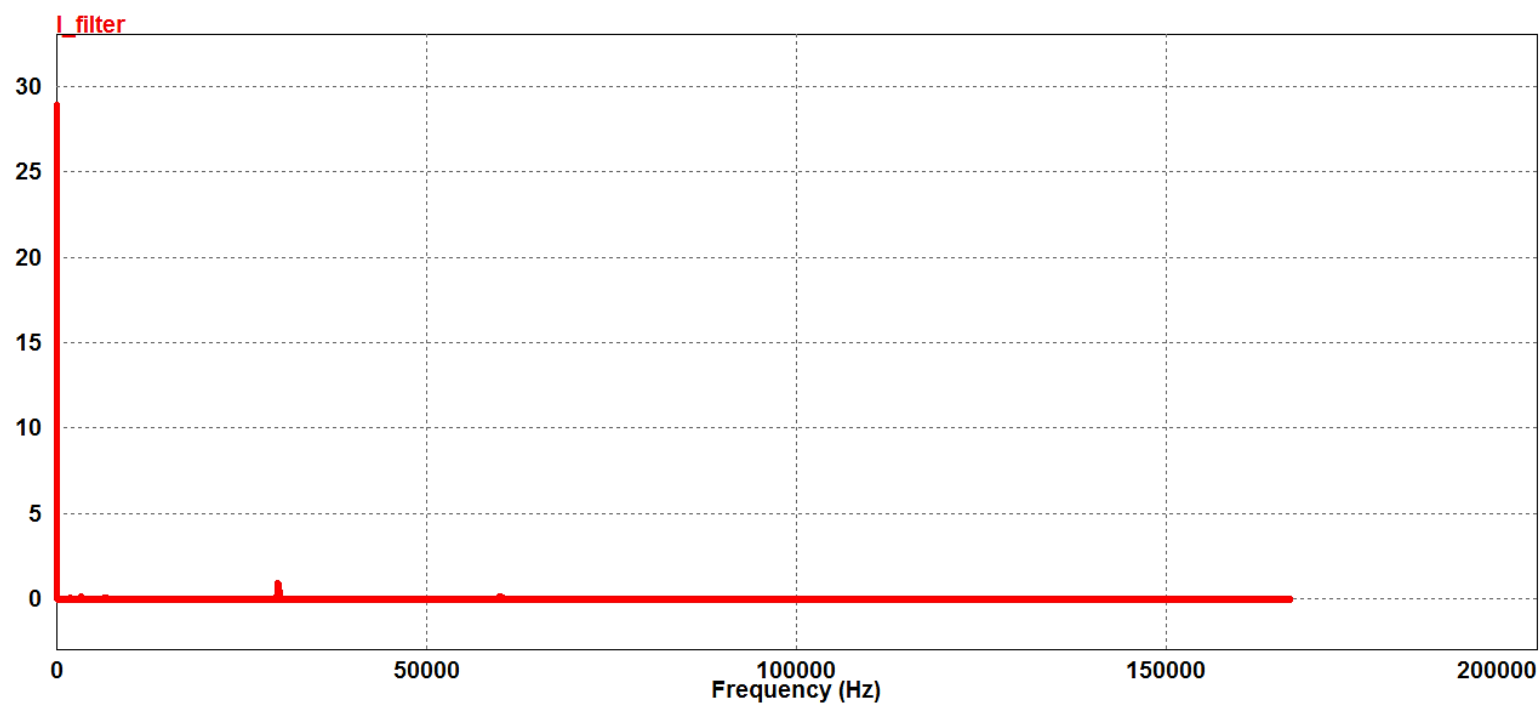

Figure 8. FFT analysis of input current of IH system with Boost PFC

\section{Calculation of THD in Input Current}

\subsection{Without Boost PFC}

The induction heating equipment (IHE) connected through the work piece without using filer is shown in Figure 3, and its simulated results are shown in PSIM software. In PSIM software the FFT analysis of input current is also done which is designed in Figure 5. It is observed from figure that the input current comprises of twelve (12) frequency elements.

$T H D=\frac{\sqrt{\sum_{n=2}^{\infty}\left(I_{\text {line }}\right)_{n, \text { rms }}^{2}}}{\left(I_{\text {line }}\right)_{1, \text { rms }}}=\frac{\sqrt{\begin{array}{l}0.0513^{2}+0.0917^{2}+0.695^{2}+0.323^{2}+0.426^{2}+0.516^{2}+ \\ 0.267^{2}+0.618^{2}+0.332^{2}+0.167^{2}+1.002^{2}+0.121^{2}\end{array}}}{3.432} \times 100 \%=47.48 \%$

\subsection{With Boost PFC}

Figure 6 shows the use of boost PFC circuit connection in induction heating equipment through the work piece. And in Figure 8 the analysis of FFT is shown when the filter is used in IHE. In Figure 8, it is observed that the harmonic components present in Figure 5 are eliminated. Harmonics that exists in the waveform of input current is much less in the system with boost PFC than the system without it. 
$\begin{aligned} T H D=\frac{\sqrt{\sum_{n=2}^{\infty}\left(I_{\text {line }}\right)_{n, r m s}^{2}}}{\left(I_{\text {line }}\right)_{1, \text { rms }}} & =\frac{\sqrt{0.015^{2}+0.182^{2}+0.015^{2}+0.187^{2}+0.1^{2}}}{27.127} \times 100 \% \\ & =1.033 \%\end{aligned}$

Table 1. Differentiation of the application of Boost PFC

\begin{tabular}{ccc}
\hline & No. of predominant harmonic components & THD \\
\hline Without the application of Boost PFC & 12 & $47.48 \%$ \\
\hline With the application of Boost PFC & 5 & $1.033 \%$ \\
\hline
\end{tabular}

\section{Conclusion}

This paper deals with the study of the design and construction of IHE, which is for both household as well as industrial applications. The various results are obtained by using PSIM software. Analysis of harmonic distortion and THD values of the input current waveforms are calculated. So, this experiment shows that the high frequency inverter, which is used for induction heating, produces an alternating magnetic field, which in turn produces eddy current loss, which is mainly a heating effect. Therefore, switching at high frequency has the intense drawback of producing harmonic distortion as well as high frequency harmonic current, and this current results in manipulating the power quality by flowing towards its supply side. Thus, a boost PFC circuit is designed, which can reduce this entire high frequency component and finally result in a strong quality of input power. A well-designed boost PFC is introduced based on a power factor correction technique that limits the EMI and RFI, the harmonic distortion, and also improves the quality of power input. As a result, THD is obtained at $47.48 \%$ of the input phase current waveform without the use of a filter, while THD is $1.033 \%$ as shown in Table 1 . In fact, the THD of the input current waveform, which is $47.48 \%$ without using a filter, indicates very poor power quality.

\section{Declarations}

\subsection{Author Contributions}

R.R. conceived the original idea. This was also discussed with D.J.B. and S.D. and then with P.N. and K.T.S. eventually, all authors discussed and agreed with the main focus and idea for this paper. The final proof-of-concept was done by R.R. using PSIM. This was then extended by S.D. and D.J.B. by performing the THD calculation in the input current waveform. K.T.S. and P.N. fixed multiple issues in the implementation, and also pointed out an important issue regarding data augmentation. The main idea behind the incorporation of Boost PFC in IH system was conceived by R.R. with many helpful suggestions from D.J.B., S.D., P.N. and K.T.S. during its simulation and proper implementation. P.N. and K.T.S. performed a detailed literature review to find out the research gap. D.J.B. and S.D. played leading role in collection and processing of data. R.R. designed the duty cycle control for Boost PFC; D.J.B. and K.T.S. designed the resonant inverters based IH system while S.D. and P.N. performed the design and analysis of parameters for inductor and capacitor selection. All the authors have given significant contribution in writing the paper. K.T.S. and P.N. were in charge of overall direction and planning. All authors discussed the results and contributed to the final manuscript. All authors have read and agreed to the published version of the manuscript.

\subsection{Data Availability Statement}

The data presented in this study are available on request from the corresponding author.

\subsection{Funding}

The authors received no financial support for the research, authorship, and/or publication of this article.

\subsection{Acknowledgements}

We would like to acknowledge our indebtedness and render our warmest thanks to Prof. Pradip Kumar Sadhu from the Indian Institute of Technology (ISM), Dhanbad for sharing his pearls of wisdom with us during the course of this research. This paper and the research behind it would not have been possible without the exceptional support of Prof. Sadhu whose expertise was invaluable in formulating the research questions and methodology. Moreover, the close guidance and supervision provided by him helped to improve the manuscript at every stage. We would also like to thank IIT (ISM) Dhanbad and Jorhat Engineering College, Assam for providing the necessary research facilities for carrying out this research.

\subsection{Declaration of Competing Interest}

The authors declare that they have no known competing financial interests or personal relationships that could have appeared to influence the work reported in this paper. 


\section{References}

[1] Xiang, X., Luo, A., \& Li, Y. (2020). Intelligent Control Method of Power Supply for Tundish Electromagnetic Induction Heating System. Journal of Modern Power Systems and Clean Energy, 8(6), 1188-1195. doi:10.35833/mpce.2019.000066.

[2] Tan, Y. Z., Chandrakant, S. P., Ang, J. S. T., Wang, H., \& Chew, J. W. (2020). Localized induction heating of metallic spacers for energy-efficient membrane distillation. Journal of Membrane Science, 606, 118150. doi:10.1016/j.memsci.2020.118150.

[3] Yang, C., Xie, J., Wu, S., Amirkhanian, S., Wang, Z., Song, J., ... Zhang, L. (2021). Enhancement mechanism of induction heating on blending efficiency of RAP - virgin asphalt in steel slag recycled asphalt mixtures. Construction and Building Materials, 269, 121318. doi:10.1016/j.conbuildmat.2020.121318.

[4] Liu, Y., Nishiyama, M., Tani, M., Kurata, M., \& Iwata, K. (2021). Steel beam with web opening reinforced by induction heating. Journal of Constructional Steel Research, 176, 106399. doi:10.1016/j.jcsr.2020.106399.

[5] Chyba, C. F., Hand, K. P., \& Thomas, P. J. (2021). Magnetic induction heating of planetary satellites: Analytical formulae and applications. Icarus, 360, 114360. doi:10.1016/j.icarus.2021.114360.

[6] Zhang, C., Wu, Y., \& Lu, Y. (2020). Experimental and numerical study on induction heating performance of quaternary nitrate - nitrite molten salt. International Journal of Energy Research, 45(2), 2211 - 2221. doi:10.1002/er.5914.

[7] Han, W., Chau, K. T., \& Zhang, Z. (2017). Flexible Induction Heating Using Magnetic Resonant Coupling. IEEE Transactions on Industrial Electronics, 64(3), 1982-1992. doi:10.1109/tie.2016.2620099.

[8] Wenxu, Y., Zhicheng, J., \& Xianling, L. (2006). Power Control for Induction Heating by Asymmetrical Pulse Density Modulation. 2006 1ST IEEE Conference on Industrial Electronics and Applications. doi:10.1109/iciea.2006.257061.

[9] Sanz-Serrano, F., Sagues, C., \& Llorente, S. (2015). Power distribution in coupled multiple-coil inductors for induction heating appliances. 2015 IEEE Industry Applications Society Annual Meeting, 52(3), 2537-2544. doi:10.1109/ias.2015.7356805.

[10] Lope, I., Acero, J., \& Carretero, C. (2016). Analysis and Optimization of the Efficiency of Induction Heating Applications with Litz-Wire Planar and Solenoidal Coils. IEEE Transactions on Power Electronics, 31(7), 5089-5101. doi:10.1109/tpel.2015.2478075.

[11] Lucia, O., Maussion, P., Dede, E. J., \& Burdio, J. M. (2014). Induction Heating Technology and Its Applications: Past Developments, Current Technology, and Future Challenges. IEEE Transactions on Industrial Electronics, 61(5), 2509-2520. doi:10.1109/tie.2013.2281162.

[12] Namadmalan, A. R., Fathi, S. H., Moghani, J. S., \& Sadeghi, S. H. (2011). Power quality improvement for three phase current source induction heating systems. 2011 6th IEEE Conference on Industrial Electronics and Applications, $2580-2584$. doi:10.1109/iciea.2011.5976028.

[13] Sarnago, H., Lucia, O., Mediano, A., \& Burdio, J. M. (2013). Modulation Scheme for Improved Operation of an RB-IGBTBased Resonant Inverter Applied to Domestic Induction Heating. IEEE Transactions on Industrial Electronics, 60(5), 20662073. doi:10.1109/tie.2012.2207652.

[14] Chudjuarjeen, S., Anawach Sangswang, \& Koompai, C. (2009). An improved LLC resonant inverter for induction heating with asymmetrical control. 2009 IEEE International Symposium on Industrial Electronics, 58(7), $2915-2925$. doi:10.1109/isie.2009.5222544.

[15] Ahmed, N. A. (2011). High-Frequency Soft-Switching AC Conversion Circuit with Dual-Mode PWM/PDM Control Strategy for High-Power IH Applications. IEEE Transactions on Industrial Electronics, 58(4), $1440-1448$. doi:10.1109/tie.2010.2050752.

[16] Pal, P., Sadhu, P. K., Pal, N., \& Sanyal, S. (2015). An exclusive design of EMI-RFI suppressor for modified half bridge inverter fitted induction heating equipment. International Journal of Mechatronics, Electrical and Computer Technology (IJMEC), 5(15), 2084-2100.

[17] Millán, I., Burdío, J. M., Acero, J., Lucía, O., \& Llorente, S. (2011). Series resonant inverter with selective harmonic operation applied to all-metal domestic induction heating. IET Power Electronics, 4(5), 587-592. doi:10.1049/iet-pel.2010.0107.

[18] Fujita, H., \& Akagi, H. (1991). A practical approach to harmonic compensation in power systems-series connection of passive and active filters. Conference Record of the 1990 IEEE Industry Applications Society Annual Meeting, 27(6), 1020-1025. doi:10.1109/ias.1990.152323.

[19] Barragan, L. A., Navarro, D., Acero, J., Urriza, I., \& Burdio, J. M. (2008). FPGA Implementation of a Switching Frequency Modulation Circuit for EMI Reduction in Resonant Inverters for Induction Heating Appliances. IEEE Transactions on Industrial Electronics, 55(1), 11-20. doi:10.1109/tie.2007.896129.

[20] Wernekinck, E., Kawamura, A., \& Hoft, R. (1987). A high frequency AC/DC converter with unity power factor and minimum harmonic distortion. 1987 IEEE Power Electronics Specialists Conference. doi:10.1109/pesc.1987.7077190. 
[21] Figueres, E., Benavent, J. M., Garcera, G., \& Pascual, M. (2007). A Control Circuit With Load-Current Injection for SinglePhase Power-Factor-Correction Rectifiers. IEEE Transactions on Industrial Electronics, 54(3), $1272-1281$. doi:10.1109/tie.2007.891987.

[22] Koertzen, H. W., van Wyk, J. D., \& Ferreira, J. A. (1995). Design of the half-bridge, series resonant converter for induction cooking. Proceedings of PESC '95 - Power Electronics Specialist Conference, 729-735. doi:10.1109/pesc.1995.474899.

[23] Suzuki, T., Ikeda, H., Yoshida, H., Shinohara, S., Honda, K., Miyamoto, T., \& Yamamoto, T. (1993). Shortwave DC-to-RF inverter to drive ultrasonic transducer. ISIE '93 - Budapest: IEEE International Symposium on Industrial Electronics Conference Proceedings, 332-335. doi:10.1109/isie.1993.268785.

[24] Suzuki, T., Nakabori, S., Ikeda, H., Yoshida, H., Honda, K., Miyamoto, T., \& Yamamoto, T. (1994). Compact 600 W DC-toRF MOSFET inverter for ultrasonic transducer at $1 \mathrm{MHz}$. Proceedings of 1994 IEEE International Symposium on Industrial Electronics (ISIE'94), 104-107. doi:10.1109/isie.1994.333140.

[25] Kifune, H., Hatanaka, Y., \& Nakaoka, M. (2003). Quasi-series-resonant-type soft-switching phase shift modulated inverter. IEE Proceedings - Electric Power Applications, 150(6), 725-732. doi:10.1049/ip-epa:20030558.

[26] Shenkman, A., Axelrod, B., \& Berkovich, Y. (2004). Improved modification of the single-switch AC-AC converter for induction heating applications. IEE Proceedings - Electric Power Applications, 151(1), 1-4. doi:10.1049/ip-epa:20030766.

[27] Sarnago, H., Lucía, Ó., Mediano, A., \& Burdío, J. M. (2013). Class-D/DE Dual-Mode-Operation Resonant Converter for Improved-Efficiency Domestic Induction Heating System. IEEE Transactions on Power Electronics, 28(3), 1274-1285. doi:10.1109/tpel.2012.2206405.

[28] Young-Sup Kwon, Sang-Bong Yoo, \& Dong-Seok Hyun. (1999). Half-bridge series resonant inverter for induction heating applications with load-adaptive PFM control strategy. APEC '99. Fourteenth Annual Applied Power Electronics Conference and Exposition. 1999 Conference Proceedings (Cat. No.99CH36285), 575-581. doi:10.1109/apec.1999.749738.

[29] Parida, N., Kumari, V., Bhaskar, D. V., \& Maity, T. (2015). Power control techniques used in high frequency induction heating applications. 2015 International Conference on Circuits, Power and Computing Technologies (ICCPCT-2015), 1-6. doi:10.1109/iccpct.2015.7159378.

[30] Carretero, C., Lucia, O., Acero, J., \& Burdio, J. M. (2015). Phase-shift modulation in double half - bridge inverter with common resonant capacitor for induction heating appliances. IET Power Electronics, 8(7), 1128-1136. doi:10.1049/ietpel.2014.0229.

[31] Meziane, B., \& Zeroug, H. (2016). Comprehensive Power Control Performance Investigations of Resonant Inverter for Induction Metal Surface Hardening. IEEE Transactions on Industrial Electronics, 63(10), 6086-6096. doi:10.1109/tie.2016.2581145. 